\title{
Desain Video Berbasis Motion Graphic untuk PPDB SMK Harapan Indonesia 1 dan 3
}

\author{
Video Design based on Motion Graphic PPDB of Smk \\ Harapan Indonesia 1 dan 3
}

\author{
Indri Handayani ${ }^{1}$, Erick Febriyanto, Ahmad Sururi \\ STMIK Raharja; Jl. Jenderal Sudirman, No.40, Babakan, \\ Kec. Tangerang, Kota Tangerang, (021) 55296992 \\ Jurusan Teknik Informatika, STMIK Raharja Tangerang \\ e-mail: ${ }^{1}$ indri@ raharja.info, erick@ raharja.info, sururi@ raharja.info
}

\begin{abstract}
Abstrak
Sekolah Menengah Kejuruan Harapan Indonesia 1 dan 3 merupakan salah satu sekolah yang berada di kota Tangerang. Sekolah Menengah Kejuruan Harapan Indonesia 1 dan 3 mempunyai 3 Jurusan yaitu Multimedia untuk Sekolah Menengah Kejuruan Harapan indonesia 1 dan Jurusan Keperawatan dan Farmasi untuk Sekolah Menengah Kejuruan Kesehatan Harapan Indonesia 3. Sejak berdirinya 2 tahun yang lalu sekolah ini dalam menyampaikan sebuah informasi masih menggunakan cara - cara tradisional yaitu dengan menyebar brosur, pasang banner di pohon, spanduk dan ke sekolah - sekolah langsung sehingga kurang menarik dan informatif, dapun masalahnya adalah agar masyarakat mengetahui keberadaan Sekolah Menengah Kejuruan Harapan Indonesia 1 dan 3 yang masih baru, tujuan dari penelitian ini adalah untuk menghasilkan video profil berbasis motion graphic untuk menunjang penerimaan peserta didik baru di Sekolah Menengah Kejuruan Harapan Indonesia 1 dan 3, manfaat dari penelitian adalah sebagai Penunjang penerimaan peserta didik baru, Dokumentasi dan media promosi untuk memajukan dan mempublikasikan ke berbagai media sosial. Metode penelitian yang digunakan adalah metode pendataan, yaitu observasi, dan wawancara, metedologi pendekatan masalah yaitu Analisis, perancangan, Pembuatan desain grafis, pengambilan gambar, editing, dubbing dan rendering, Hasil yang diperoleh dari penelitian ini adalah terbentuknya desain video berbasis motion graphic untuk mempromosikan sekolah maupun perusahaan, karena lebih menarik dan lebih efektif untuk menunjang penerimaan peserta didik baru di Sekolah Menengah Kejuruan Harapan Indonesia 1 dan 3.
\end{abstract}

Kata kunci-Motion Graphic, Video Desain, Media informasi, Sekolah Menengah Kejuruan Harapan Indonesia 1 dan 3, Penerimaan Peserta Didik Baru

\section{Abstract}

Vocational School of Harapan Indonesia 1 and 3 is one of the schools located in the city of Tangerang, Vocational School of Harapan Indonesia 1 and 3 has 3 Departments are Multimedia for Vocational School of Harapan Indonesia 1 and Department of Nursing and Pharmacy for Health Vocational School of Harapan Indonesia 3. Since the establishment of 2 years ago this school in conveying an information still using traditional ways that is by spreading brochures, pairs of banners on trees, banners and to the schools - direct schools so less interesting and informative, as for the problem is so that people know the existence of the new vocational schools of Harapan Indonesia 1 and 3, the purpose of this research is to 
produce motion graphic based video profile to support the acceptance of new learners in Vocational School of Harapan Indonesia 1 and 3, the benefits of research is as Support acceptance of new learners, Documentation and promotional media to promote and publish to various social media. The research method used is the method of data collection, that is observation, and interview, metodologi approach problem that is Analysis, designing, making of graphic design, shooting, editing, dubbing and rendering, The results obtained from this study are the formation of motion graphic-based design videos to promote schools and companies, because it is more attractive and more effective to support the acceptance of new students in Indonesia Hope Vocational High School 1 and 3.

Keywords - Motion Graphic, Design Video, Media information, Vocational School of Harapan Indonesia 1 and 3, Acceptance of New Learners

\section{PENDAHULUAN}

Sekolah Menengah Kejuruan Harapan Indonesia 1 dan 3 merupakan salah satu SMK baru di kota Tangerang. Tujuan dari SMK harapan indonesia yaitu menjadikan para siswa / i menjadi calon tenaga kesehatan dan teknologi informatika secara profesional, mandiri dan berkelanjutan, sehingga menghasilkan lulusan yang profesional dan bermutu serta kompetitif secara nasional dan global. SMK Harapan Indonesia 1 dan 3 mempunyai 3 Jurusan yaitu Multimedia untuk SMK Harapan Indonesia 1, Jurusan Keperawatan dan Farmasi untuk SMK Kesehatan Harapan Indonesia 3. Adapun tujuan dari 3 jurusan tersebut adalah multimedia Bertujuan membekali perserta didik dengan pengetahuan, sikap siswa yang kreatif, mandiri, dan berstandar global dan dilandasi sikap entrepreneupship. Di jurusan Multimedia ini anak didik berpeluang menjadi : Graphic design, Art Director, Photographer, Digital Ilustrator, Advertising, Progamer, dan Game Devlopment.

Keperawatan Bertujuan membekali anak didik dengan pengetahuan, sikap, dan keterampilan dalam mengaplikasikan pengetahuan dan keterampilan keperawatan yang dimiliki untuk mengemban tugas social dimasyarakat. Di jurusan Keperawatan ini anak didik berpeluang menjadi : Asisten Perawat, Homecare, Rumah Bersalin, Puskesmas, dan Klinik Kesehatan.

Farmasi Bertujuan membekali perserta didik dengan pengetahuan,sikap,dan keterampilan dalam meracik obat, prinsip pembuatan obat, dan dasar-dasar kefarmasian. Di jurusan Farmasi ini anak didik berpeluang menjadi : Asisten Apoteker ,Pelayan obat dirumah sakit, Serta berwirausaha.

Sekolah Menengah Kejuruan Harapan Indonesia 1 dan 3 saat ini dalam penyampain informasi kepada masyarakat masih menggunakan cara - cara konevensional seperti sebar brosur, pasang spanduk, pasang banner di pohon, hingga datang ke sekolah - sekolah sehingga masih kurang efektif dan promotif. seiring berkembangnya zaman, media audio visual semakin berkembang dan banyak digunakan semua kalangan karena dianggap mudah ditangkap dalam penyampain informasi.

Berdasarkan permasalahan yang telah di uraikan maka penulis melakukan penelitian dengan mengambil judul yaitu " Pembuatan Video Profil Berbasis Motion Graphic untuk Menunjang Penerimaan Peserta Didik baru di SMK Harapan Indonesia 1 dan 3 ". Di harapkan dengan pembuatan media audio visual ini masyarakat mudah mendapatkan informasi tentang keberadaan sekolah ini, sehingga membantu dalam penerimaan peserta didik baru tahun $2018 / 2019$.

\section{METODE PENELITIAN}

Metode penelitian yang digunakan adalah metode pendataan, yaitu observasi, dan wawancara, metedologi pendekatan masalah yaitu Analisis, perancangan, Pembuatan desain grafis, pengambilan gambar, editing, dubbing dan rendering, Hasil yang diperoleh dari 
penelitian ini adalah diharapkan terbentuknya desain video berbasis motion graphic untuk menunjang penerimaan peserta didik baru di Sekolah Menengah Kejuruan Harapan Indonesia 1 dan 3.

\section{Permasalahan}

Dalam proses penyampaian Informasi di Sekolah Menengah Kejuruan Harapan Indonesia 1 dan 3 masih ada kendala dan kekurangan dalam menyampaikan informasi ke masyarakat terutama dalam Penerimaan peserta didik baru atau PPDB, permasalahan tersebut diantaranya adalah sebagai berikut :

a. Belum adanya video Profil di Sekolah Menengah Kejuruan Harapan Indonesia 1 dan 3

b. Bagaiamana cara membuat video profil sekolah berbasis motion graphic yang menarik dan inovatif

c. Bagaimana video profil ini bisa menunjang penerimaan peserta didik baru di SMK Harapan Indonesia 1 dan 3

\section{Pemecahan Masalah}

Setelah mengamati dan meneliti dari beberapa permasalahan yang terjadi pada SMK Harapan Indonesia 1 dan 3 , terdapat beberapa alternatif pemecahan dari permasalahan yang dihadapi yaitu, dengan membuat sebuah desain video berbasis motion graphic untuk menunjang peserta didik baru.

Dari permasalahan yang disebutkan diatas maka dibuatlah sebuah Desain Video dengan alur sebagai berikut:

a. Pembuatan Desain

Pembuatan desain dilakukan untuk merancang tampilan dan karakter dari setiap icon yang akan dijadikan sebuah animasi di Software Adobe After Effect CS6, pembuatan desain menggunakan Software Adobe Ilustrator CS6.

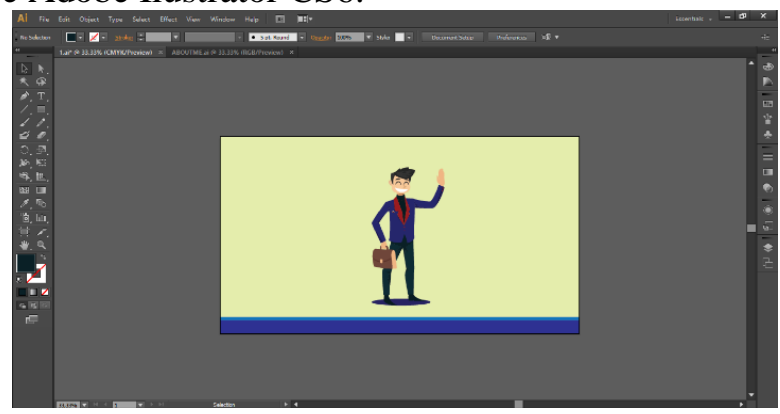

Gambar 1. Pembuatan Karakter

Gambar 1 merupakan tampilan pembuatan character desain menggunakan software Adobe Ilustrator CS6. Pada gambar tersebut terlihat gambar tampilan awal pada pembuatan gambar Karakter desain.

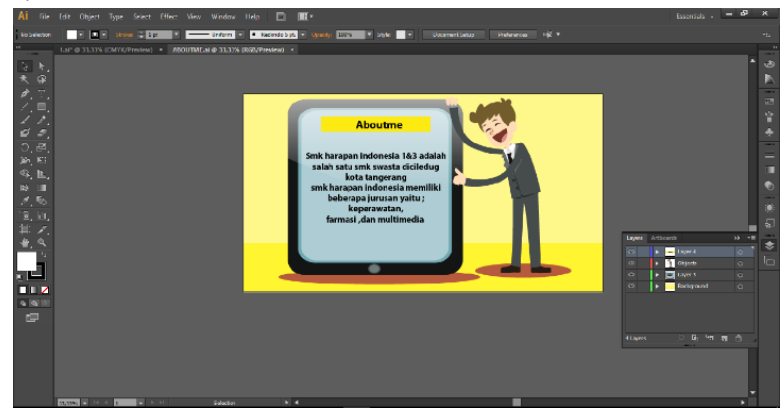

Gambar 2. Pembuatan objek perlayer 
Gambar 2 merupakan pembuatan desain di buat per layer jadi setiap objek atau icon mempunyai layer sendiri, misalnya objek mata mempunyai layer sendiri, karena nantinya setiap objek akan dijadikan sebuah animasi.

b. Pembuatan Opening

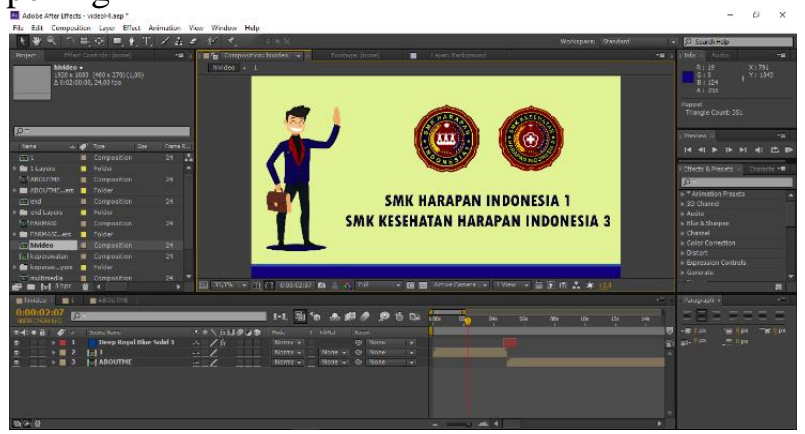

Gambar 3. Pembuatan Opening

Gambar 3 Untuk pembuatan judul dilakukan dengan menggunakan Software Adobe After Effect CS6. Desain yang sebelumnya telah dibuat di Adobe Ilustrator CS6 di import ke Adobe After Effect CS6 untuk dijadikan Animasi Motion Graphic. Hasil akhir pembuatan judul dirender MP4.

c. Perekaman Suara

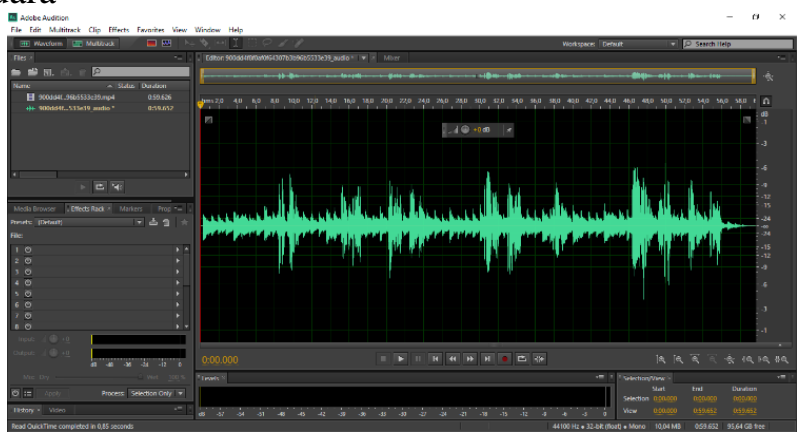

Gambar 4. Perekaman suara

Gambar 4 merupakan Berkas suara digital digunakan untuk mengisi suara (dubbing) dari narasi yang telah dibuat untuk mengisi desain video, agar video yang ditampilkan akan semakin menarik. Dalan perekaman suara menggunakan Software Adobe Audition CS6, microphone dan speaker. Hasil menyimpan suara direkam kedalam format mp3.

d. Tahap Penganimasian Motion Graphic

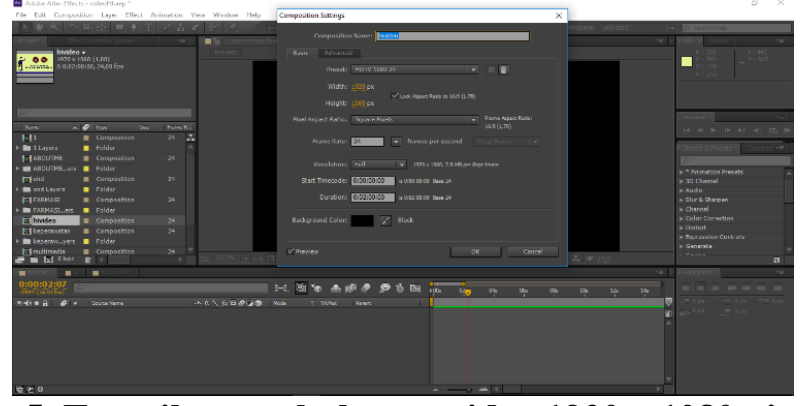

\section{Gambar 5. Tampilan awal ukuran video $1920 \times 1080$ pixel 24 fps}

Gambar 5 merupakan tahap membuat Animasi Motion Graphic Software yang digunakan adalah Adobe After Effect CS6. Seluruh desain yang telah dibuat di Adobe Ilustrator di import ke Adobe After Effect CS6. Menggunakan format video 16:9 dengan ukuran $1920 \mathrm{x}$ 1080 pixel, dengan 24 Fps. Pada tahap ini dilakukan penggabungan antara adegan satu dengan adegan berikutnya, untuk disesuaikan dengan naskah. 


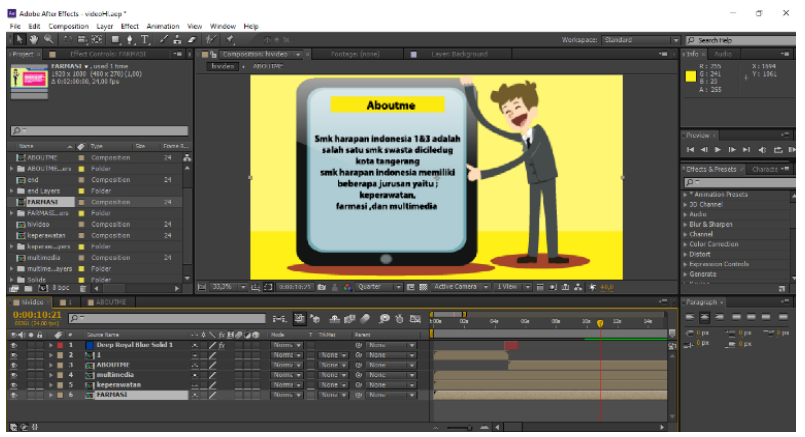

Gambar 6. Penggabungan per layer

Gambar 5 merupakan tahap penggabungan perlayer di adobe after effect seluruh objek yang dibuat di gabungkan dan dibuat perlayer sehingga bisa dianimasikan satu persatu.

e. Tahap Penggabungan Video

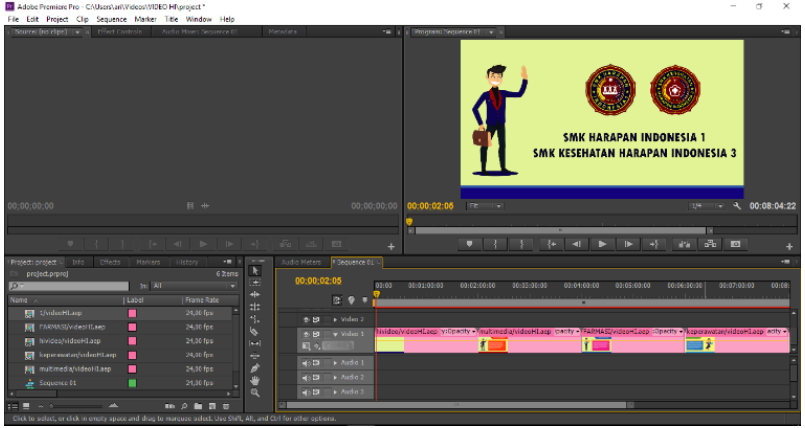

Gambar 7. Penggabungan video animasi

Gambar 7 merupakan Proses editing dilakukan dengan Software Adobe Premier pro CS6. Pada tahap ini dilakukan penggabungan antara video animasi yang telah dibuat, dubbing audio (pengisi suara), dan backsound Effect untuk membuat desain video menjadi lebih menarik.

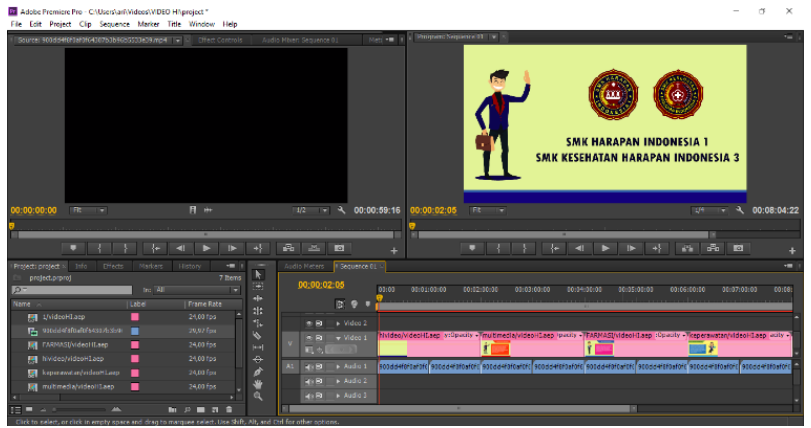

Gambar 8. Penggabungan video animasi, audio dan backsound effect

Gambar 8 merupakan penggabungan Video Animasi, Audio dan Backsound tahap ini merupakan tahap final dari pembuatan Animasi sehingga sudah bisa dilihat secara keseluruhan Animasi yang telah dibuat. 


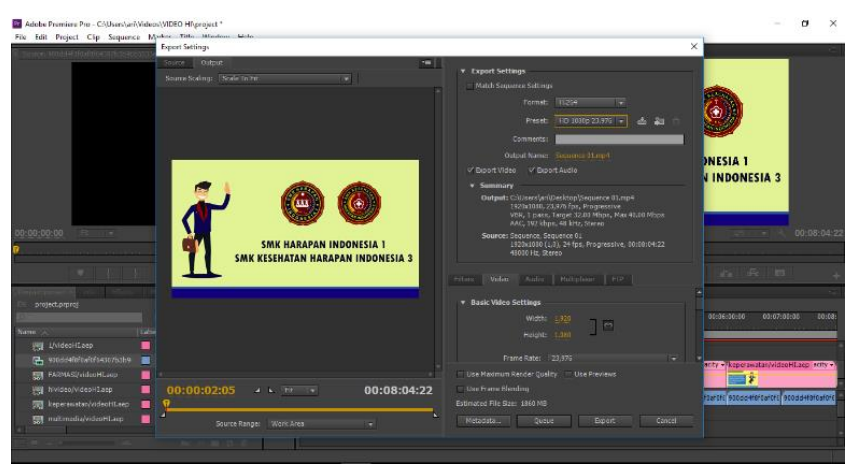

Gambar 9. Proses Rendering

Gambar 9 merupakan proses render dalam bentuk file mp4 dengan cara memilih file > Exsport > Setting Video format. Lalu pilih file penyimpanan file. File video yang telah dirender kemudian diaplikasikan kedalam bentuk DVD.

\section{Literature Review}

1. Video Sebagai E-Portofolio Mahasiswa untuk Meningkatkan Keterampilan Mahasiswa,2015, adalah salah satu judul artikel yang dibuat oleh Giandari Maulani (Alumni Universitas Budi Luhur Program Studi Magister Komputer), Untung Rahardja (Alumni Universitas Indonesia Program Studi Magister Teknologi Informasi), Lalita Tri Adila (Mahasiswa STMIK Raharja) . Penelitian ini membahas Pemanfaatan teknologi yang berkembang yang dimanfaatkan dosen untuk mengubah cara penilaian siswa. Jurnal ini akan membahas tentang bagaimana teknik penilaian, penilaian e-portofolio juga membahas tentang masalah yang di hadapi dalam penilaian portofolio.[1]

2. Perancangan video profile sebagai media promosi stmik cic dengan tehnik motion graphic menggunakan perangkat lunak komputer graphic,2017, adalah salah satu judul Jurnal yang dibuat oleh Fadhly Abdillah, Damar Adhiguna, Agus Sevtiana selaku mahasiswa Sekolah Tinggi Teknologi CIC Cirebon. . Penelitian ini menjelaskan tentang pembuatan media promosi berbasis motion graphic menggunakan perangkat lunak komputer graphic.[2]

3. Perancangan Sistem Informasi Pengelolaan Retribusi Pengujian Kendaraan Bermotor Kabupaten Aceh Utara, 2015, adalah salah satu judul jurnal yang dibuat oleh Dahlan Abdullah ,Penelitian ini bertujuan untuk merancang sebuah sistem informasi mengenai pengelolaan retribusi, Perancangan dilakukan dengan menggunakan DFD dan ERD untuk memodelkan data dan proses.[3]

4. Perancangan Video Company Profile Lembah Kamuning Dairy Farm, Desa Cigugur, Kuningan dengan Teknik Motion Graphic, 2016, adalah salah satu jurnal yang dibuat oleh Yessica Brigitta , Prof. Dr. Ir. Eko Sediyono, M.Kom, Frederik Samuel Papilaya, S.Kom., M.Cs. Penelitian ini bertujuan untuk membuat video company profile dengan Teknik Motion Graphic. Selain itu, bertujuan untuk memberikan informasi yang berguna kepada anggota Koperasi Produksi Gapura Sehat dan masyarakat yang ingin mengetahui lebih lanjut mengenai Lembah Kamuning Dairy Farm. .[4]

5. Evolution of Art Form of Video Animation Design Under the Background of Computer Graphics System Development,2017, adalah salah satu judul yang dibuat oleh Jiang Tan, dari University Of Shanghai for Science and Technology. The journal aims to describe, the main characteristics and methods in the design and manufacture of animated films.[5]

6. Pembuatan Video Profil Smart Preschool Kepunton Solo ,2014, adalah salah satu judul yang dibuat oleh Budi Santoso, Indonesian Journal on Networking and Security . Penelitian ini bertujuan untuk memberikan informasi dan promosi, dalam metode penelitian yang dibuat yaitu study kepustakaan, Observasi, Wawancara, perancangan Storyboard, pembuatan video, uji coba dan implementasi .[6] 
7. Pembuatan Media Audio Visual menggunakan Videoscribe Sebagai Penyajian Informasi Pembelajaran Pada Kelas Sistem Informasi ,2016, adalah salah satu judul yang dibuat oleh Muhammad Yusup, Quratul Aini dan Komala dwi Putri. Penelitian ini menjelaskan tentang pembuatan media pembelajaran menggunakan Videoscribe sebagai penyajian informasi pada kelas sistem informasi.[7]

Kelemahan dari keseluruhan artikel tersebut adalah metode yang dilakukan masih belum efektif, sehingga penulis perlu melakukan penilitian yang baru. Kesamaannya adalah menggunakan Teknik Motion Graphic sedangkan perbedaan dari pembuatan artikel yang penulis buat dengan yang sudah ada adalah penulis membuat Karakter Desain satu persatu menggunakan software Adobe Ilustrator CS 6, untuk membuat animasinya menggunakan software Adobe After Effect CS 6 dan Adobe Premier CS6.

\section{HASIL DAN PEMBAHASAN}

Skema Alur Kerja

a. Tampilan Pembuka

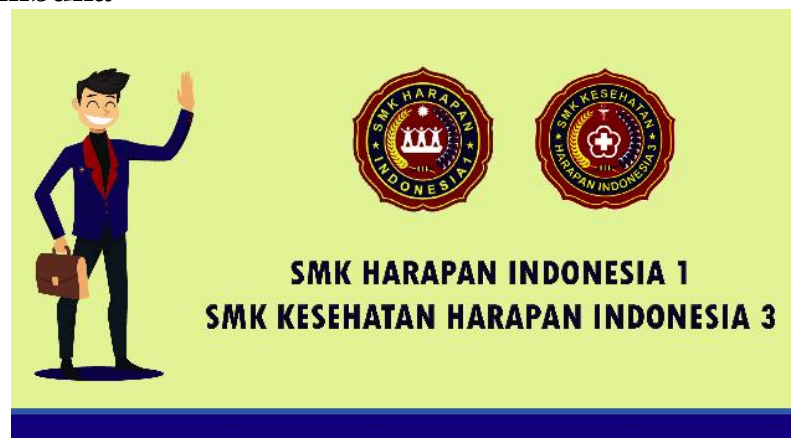

Gambar 10. Tampilan Opening

Gambar 10 merupakan tampilan awal dari video profil dibuat dengan software After Effect CS6 yaitu berupa bamper opening yang bertuliskan SMK Harapan Indonesia 1 dan SMK Harapan Indonesia 3.

\section{b. Tampilan Isi}

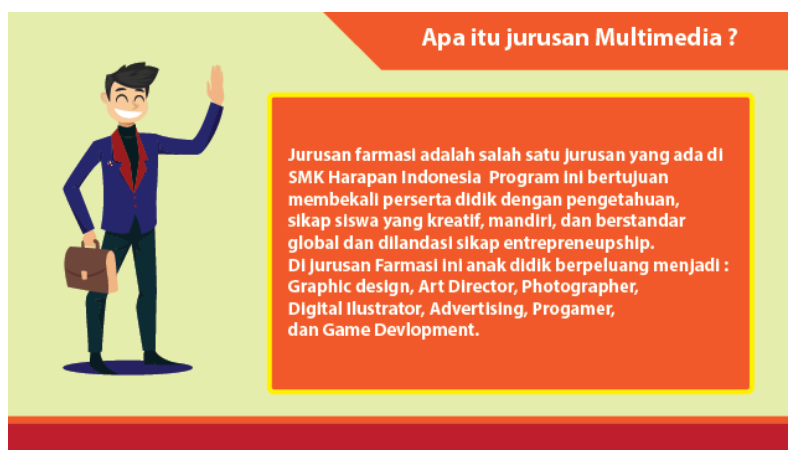

Gambar 11. Tampilan penjelasan jurusan

Gambar 11 merupakan tampilan isi dalam video profil smk Harapan Indonesia 1 dan 3, terdapat gambar - gambar (Karakter) animasi yang berjalan yang sedang menjelaskan masing masing jurusan yang ada disekolah tersebut.

\section{c. Tampilan Penutup}




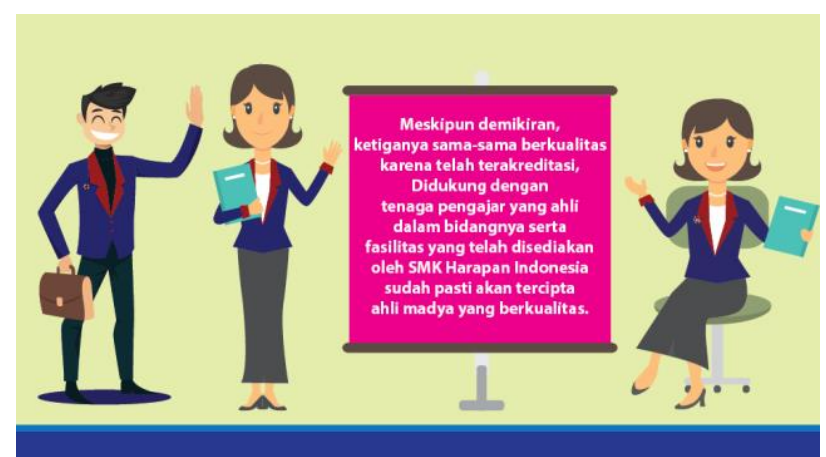

Gambar 12. Tampilan Akhir dari video

Gambar 12 merupakan Tampilan penutup di akhiri dengan penjelasan dari masing - masing jurusan berupa kesimpulan dan keunggulan dari Smk Harapan Indonesia 1 dan 3.

d. Media Penyimpanan

Setelah melalui proses analisis dan perancangan sistem dalam pembuatan video profile berbasis motion graphic. Langkah terakhir yang harus dilakukan adalah mengimplementasikan sistem tersebut kedalam beberapa media yang tersedia seperti DVD, dan youtube . Program yang digunakan untuk mengcopynya kedalam DVD adalah program Ashampo Burning Studio 2012 .

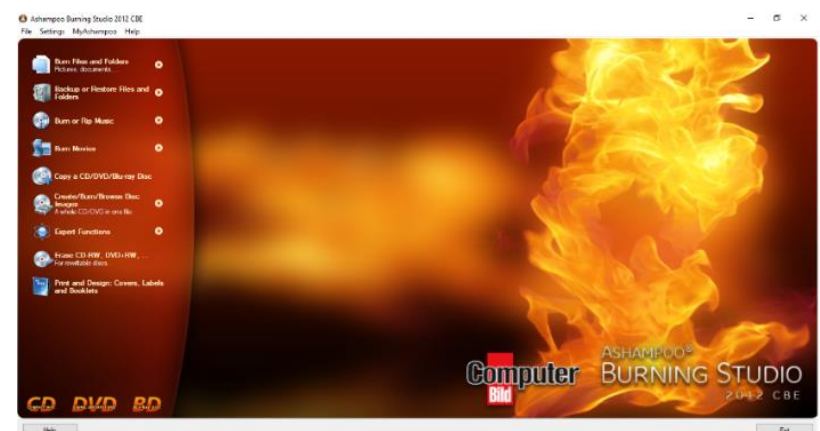

Gambar 13. Burning Video

Gambar 13 merupakan tampilan awal dari program Ashampo Burning Studio 2012 yang digunakan untuk memburning video animasi yang sudah jadi.
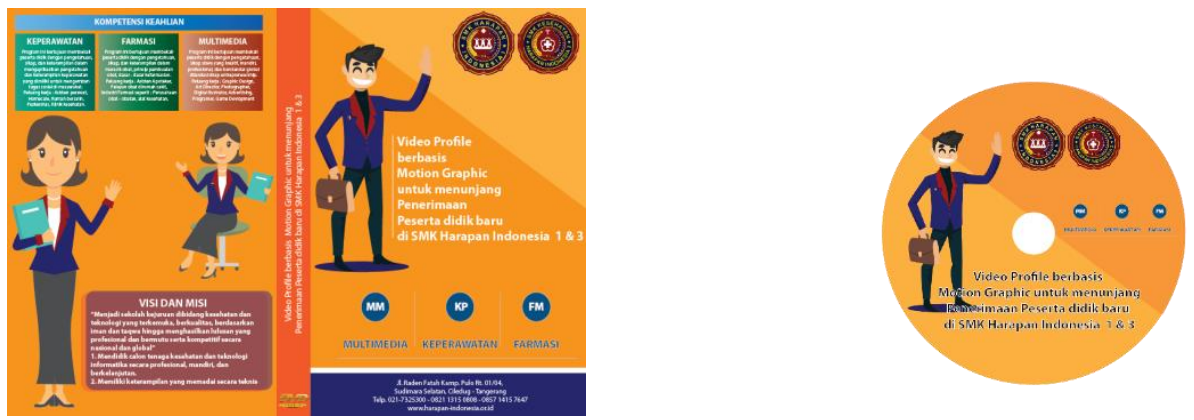

Gambar 14. Cover dan sampul DVD

Gambar 14 merupakan hasil pembuatan Desain Video dalam bentuk DVD dikemas dengan penambahan cover dan sampul DVD. 


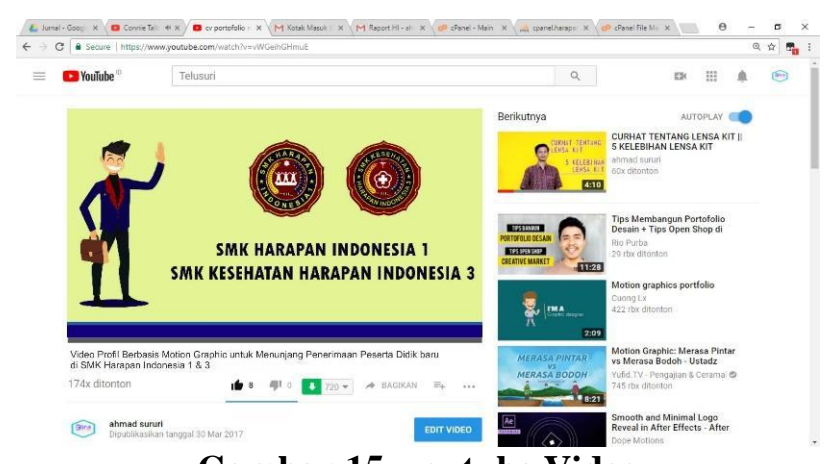

Gambar 15. youtube Video

Gambar 15 merupakan hasil penerapan dari artikel yang dibuat hasil karya tersebut di implementasikan/terapkan di media sosial youtube.

Manfaat dari penilitian yang dibuat ini adalah untuk mempromosikan sekolah maupun perusahaan, karena lebih menarik dan lebih efektif, dengan media DVD dan media sosial youtube memudahkan masyarakat luas untuk melihat lebih nyata informasi tentang Sekolah Menengah Kejuruan Harapan Indonesia 1 dan 3 dengan informasi yang lengkap sehingga dapat digunakan dengan baik untuk dijadikan media Informasi dan promosi.

\section{KESIMPULAN}

Dengan demikian dapat disimpulkan bahwa Desain Video berbasis Motion Graphic sangat membantu dalam mempromosikan sekolah maupun perusahaan, karena lebih menarik dan lebih efektif, dengan media DVD dan youtube profil memudahkan masyarakat luas untuk melihat lebih nyata informasi tentang Sekolah Menengah Kejuruan Harapan Indonesia 1 dan 3 dengan informasi yang lengkap sehingga dapat digunakan dengan baik untuk dijadikan media Informasi dan promosi.

Dengan demikian diharapkan dengan adanya Desain Video tersebut mampu untuk membantu dalam menyampaikan informasi ataupun mempromosikan sekolah tersebut untuk menunjang penerimaan peserta didik baru tahun ajaran 2018/2019.

\section{SARAN}

Dari hasil penelitian ini masih terdapat banyak kekurangan terutama dalam pembuatan Video Motion Graphic, sehingga kedepannya perlu pengembangan lagi dalam teknik pembuatan karakter maupun pembuatan animasi agar informasi yang ingin disampaikan bisa tersampaikan lebih baik lagi.

\section{UCAPAN TERIMA KASIH}

Penulis mengucapkan terima kasih kepada pihak manajemen Sekolah Tinggi Manajemen Informatika dan Komputer (STMIK) Raharja yang telah memberi dukungan terhadap penelitian ini. Terima kasih kepada seluruh rekan - rekan akademik yang telah memberikan masukan, dukungan dan bimbingan dalam menyelesaikan penelitian ini, tanpa adanya rekan - rekan akademik penulis tidak dapat menyelesaikan jurnal ini dengan baik. 


\section{DAFTAR PUSTAKA}

[1] Maulani, G., Rahardja, U., Adila, L.T., Universitas, A., Luhur, B., Studi, P., ...Informasi, T. (2016). Video Sebagai E-Portofolio Mahasiswa Untuk Meningkatkan Keterampilan Mahasiswa, Jurnal Ilmiah CCIT Raharja, 9(2), 225-239

[2] Abdillah, F., Adhiguna, D., \& Sevtiana, A. (2017). Perancangan Video Profile Sebagai Media Promosi STMIK CIC Dengan Tehnik Motion Graphic Menggunakan Perangkat Lunak Komputer Graphic, 7(1),74-85.

[3] Abdullah, D. (2015). Perancangan sistem informasi pengelolaan retribusi pengujian kendaraan bermotor kabupaten Aceh utara. Jurnal ilmiah SISFOTENIKA, 5(5), 167177.

[4] Brigitta, Y. (2016). Perancangan Video Company Profile Lembah Kamuning Dairy Farm, Desa Cigugur, Kuningan dengan Teknik Motion Graphic. Artikel Ilmiah, 123.

[5] Tan, J. (2017). Evolution of Art Form of Video Animation Design Under the Background of Computer Graphics System Development, (Ssme), 150-155.

[6] Santoso, B. (2014). Pembuatan Video Profil Smart Preschool Kepunton Solo. Indonesian Journal on Networking and Security, 3(1), 53-58.

[7] Yusup, M., Aini, Q., \& Pertiwi, K. (2016). Media Audio Visual Menggunakan Videoscribe Sebagai Penyajian Informasi Pembelajaran Pada Kelas Sistem Operasi. Technomedia Journal, l(1), 126-138. Diambil dari http://ijc.ilearning.co/index.php/TMJ/article/view/8. 